\title{
Strategi Pendidikan Kristen dalam Pembentukan Warga Gereja yang Unggul dan Berkarakter Berdasarkan Perspektif Kristiani
}

\author{
Kalis Stevanus \\ Sekolah Tinggi Teologi Tawangmangu \\ kalisstevanus91@gmail.com \\ Nathanail Sitepu \\ STTI Harvest Semarang \\ psnail21@gmail.com
}

\begin{abstract}
Character education is an urgent need for quality Indonesian human development. Character education, apart from taking place in the context of the family and school, also takes place in the church environment. The purpose of this paper is to explain the significance of the church's strategic role as an educational agent and facilitator in shaping church members with Christ's character. The research method used is qualitative research with theological studies using the Bible and literature according to the subject, then analyzed and presented descriptively. From this research, it can be concluded that there are two strategies of the church in forming young generations with Christian characteristics, namely (1) the church must complete its wages, especially families so that the family functions as a place where Christian character and values live, grow and develop in children. ; (2) the church must equip its members who are teachers so that they are committed to Christ's call for the development of teacher professionalism.
\end{abstract}

Keywords: Church; Character building; Christian Education

\begin{abstract}
Abstrak
Pendidikan karakter merupakan kebutuhan yang urgen bagi pembangunan manusia Indonesia yang berkualitas. Pendidikan karakter selain berlangsung di dalam konteks keluarga, dan sekolah, juga terjadi dalam lingkungan gereja. Tujuan penulisan ini adalah menjelaskan signifikansi peran strategis gereja sebagai agen pendidikan dan fasilitator dalam membentuk warga gereja berkarakter Kristus. Metode penelitian yang digunakan adalah penelitian kualitatif dengan kajian teologis dengan memanfaatkan Alkitab dan literatur yang sesuai pokok bahasan, kemudian dianalisis dan disajikan secara deskriptif. Dari penelitian tersebut disimpulkan ada dua strategi gereja dalam membentuk generasi muda yang berkarakter kristiani, yaitu (1) gereja harus melengkapi warganya khususnya keluarga-keluarga agar keluarga berfungsi menjadi tempat di mana watak, dan nilai-nilai kristiani hidup, bertumbuh dan berkembang dalam diri anak; (2) gereja mesti memperlengkapi warganya yang berprofesi guru agar mereka komitmen terhadap panggilan Kristus bagi pengembangan profesionalisme keguruan.
\end{abstract}

Kata Kunci: Gereja; Pembentukan Karakter; Pendidikan Kristen 


\section{PENDAHULUAN}

Tulisan ini berangkat dari keprihatian penulis melihat kondisi akhirakhir ini aneka kekerasan terjadi di masyarakat. Orang mudah emosi, mudah rusuh, tidak sabar dan menjadi sangat agresif disebabkan hal-hal sepele akhirnya melakukan tindakan kekerasan baik verbal maupun non verbal kian banyak. Tak dapat dipungkiri semua ini berkaitan dengan persoalan karakter.

Salah salah usaha yang gencar dilakukan oleh pemerintah Indonesia akhir-akhir ini adalah perihal pembangunan karakter. Pemerintah Indonesia mengambil positioning mensosialisasikan karakter sebagai culture untuk mengatasi pelbagai tantangan dan masalah kemerosotan moralitas di tengahtengah masyarakat. Pembangunan karakter berkaitan erat dengan kualitas Sumber Daya Manusia (SDM) di dalam pembangunan nasional. ${ }^{1}$ Dikemukakan oleh Stevanus, untuk meningkatkan kualitas SDM masyarakat di Indonesia dapat dilakukan melalui pendidikan. Pendidikan mampu mensosialisasikan dan melibatkan segenap masyarakat dalam menumbuhkembangkan nilai-nilai kemanusian, nilai-nilai kebajikan yang

\footnotetext{
${ }^{1}$ Kalis Stevanus, "Tujuh Kebajikan Utama Untuk Membangun Karakter Kristiani Anak," BIA': Jurnal Teologi dan Pendidikan Kristen Kontekstual, Vol.1, No.1 (2018), 79-95.
}

tidak bertentangan dengan nilai-nilai luhur budaya bangsa Indonesia. Nilai-nilai tersebut seperti gotong-rotong, kekeluargaan, musyawarah untuk mencapai mufakat, toleransi, cinta kasih, cinta tanah air, dan sebagaianya. Sebab tidak dapat dipungkiri kegagalan atau kejatuhan seseorang bukan disebabkan oleh kurangnya kemampuan (capability), keahlian (skill) dan pengetahuan (knowlegde), melainkan lemahnya karakter. $^{2}$

Guna menyelesaikan masalahmasalah tersebut untuk menghasilkan manusia unggul dibutuhkan penguatan karakter SDM yang kuat. Salah satu aspek yang dapat dilakukan untuk mempersiapkan karakter SDM yang kuat adalah melalui pendidikan. Benar, apa yang dikatakan Stevanus, bahwa melalui pendidikan dapat mengoptimalkan upaya pembangunan karakter bangsa Indonesia melalui pembentukan karakter pada masing-masing individu. ${ }^{3}$

Seperti yang dikemukakan Nuhamara, pemerintah Indonesia secara serius menyadari keterpurukan karakter

${ }^{2}$ Kalis Stevanus, "Pemimpin Kristen Di Era Globalisasi," Jurnal : The Message Vo.2, No.1 (2014): 7-8.

${ }^{3}$ Kalis Stevanus, "Samuel Soukotta Sosok Pendidik Karakter Kristen," in Festschrift: Sam Soukotta Sang Pemimpin Karakter Kristen, ed. Hendro H. Siburian dan Firman Panjaitan, 1st ed. (Surakarta: Sekolah Tinggi Teologi Tawangmangu, 2020), 21. 
masyarakat antara lain nampak menggejala dan merajalelanya korupsi, politik uang, kekerasan, terkikisnya nilai-nilai luhur bangsa dan lain-lain, telah mengambil inisiatif pada pembangunan karakter bangsa, yaitu menempatkan pendidikan karakter sebagai misi pertama dari delapan misi guna mewujudkan pembangunan nasional. ${ }^{4}$

Pelaksanaan pendidikan karakter selain telah dibuat dalam bentuk silabus atau kurikulum yang dikaitkan dengan nilai-nilai luhur sebagai warisan karakter bangsa Indonesia, juga dibuat dalam pelbagai kegiatan seperti seminar yang bertemakan pendidikan karakter yang digagas baik oleh para pakar, praktisi maupun pemerhati pendidikan. Tahun 2010 itu dapat disebut sebagai tahun bagi pendidikan karakter di Indonesia.

Itu sebabnya pendidikan karakter menjadi gerakan nasional yang menjadikan pendidikan karakter adalah hal yang urgen dalam kehidupan berbangsa dan bernegara. Karakter berperan sebagai landasan dan kekuatan sehingga bangsa ini menjadi bangsa yang bermartabat dan tidak mudah dipengaruhi oleh budaya asing yang tidak sesuai dengan budaya bangsa Indonesia.

\footnotetext{
${ }^{4}$ Daniel Nuhamara, "Pengutamaan Dimensi Karakter Dalam Pendidikan Agama Kristen,” Jurnal Jaffray Vol.16, No.1 (2018): 94.
}

Uraian di atas menunjukkan betapa urgennya pembangunan karakter bagi bangsa ini. Muncul pertanyaan: siapakah yang bertanggungjawab untuk membangunnya? Tak dapat dibantah, bahwa semua unsur masyarakat Indonesia memiliki tanggung jawab membangun karakter masyarakat sesuai kapasitas masing-masing. Bahkan komunitas terkecil dalam masyarakatpun turut bertanggungjawab. $^{5}$ Hal ini juga ditegaskan Sidjabat bahwa pendidikan berlangsung seumur hidup dan dilaksanakan di dalam lingkungan keluarga, sekolah dan masyarakat. Karena itu, pendidikan merupakan tanggung jawab bersama antara keluarga, masyarakat dan pemerintah. Menurut Sidjabat, pelaksanaan PAK di tengah keluarga perlu dikembangkan oleh gereja. Gereja pun harus melengkapi keluarga Kristen agar mampu menjadi tempat di mana watak, dan nilai-nilai hidup bertumbuh dan berkembang dalam diri anak. Gereja mesti memampukan keluarga menjadi lingkungan pengajar dalam segi-segi iman, keterampilan dan sikap mental bagi anak. ${ }^{6}$

${ }^{5}$ Kalis Stevanus, Menjadi Orangtua Bijak: Solusi Mendidik Dan Melindungi Anak Dari Pengaruh Pergaulan Buruk (Yogyakarta: Yayasan Pusataka Nusatama, 2016), 28.

${ }^{6}$ B.S. Sidjabat, Strategi Pendidikan Kristen: Suatu Kajian Teologis-Filosofis (Yogyakarta: Andi Offset, 1996), 119-120. 
Pendidikan yang baik merupakan senjata yang ampuh melawan kebodohan, kemiskinan, dan penindasan. Gereja yang sehat juga memerlukan sumber daya manusia yang baik untuk berjalannya roda pelayanan dan juga pertumbuhan gereja, bahkan penulis berpendapat bahwa pertumbuhan rohani juga memiliki keterkaitan dengan pertumbuhan iman. Gereja perlu untuk serius di dalam memberikan perhatian kepada bidang pendidikan yang berbasis Kristen. Memang harus diakui pada umumnya gereja sudah berpartisipasi dalam dunia pendidikan melalui diakonia, yaitu menyediakan beasiswa kepada anggota jemaat yang tidak mampu. Namun penulis ingin agar gereja mengambil keterlibatan lebih jauh lagi. Gereja benar-benar menyadari bahwa pendidikan adalah bagian yang tidak terpisahkan dari gereja itu sendiri.

$$
\text { Pendidikan Kristen baik }
$$
diselenggarakan secara non-formal di gereja maupun pendidikan formal, tetap harus mengedepankan keseimbangan pembinaan spiritual atau kerohanian yang berdampak pada pembentukan karakter kristiani peserta didiknya. Namun pembinaan dalam ranah intelektual juga perlu digarap serius tanpa dianggap sebagai musuh dari pembinaan kerohanian. Keduanya tidak boleh dipertentangkan sebaiknya harus dilakukan secara simultan. Sebagaimana dikemukakan Kalis Stevanus, mengingat kehidupan kerohanian atau pembentukan watak/karakter peserta didik saat ini semakin merosot, maka penekanan pada kehidupan kerohanian guna menghasilkan manusia yang berkarakter kristiani yang berpusat pada Alkitab dan pribadi Yesus Kristus perlu ditingkatkan lagi. ${ }^{7}$

Dalam tulisan ini, yang menjadi lokus pembahasan penulis adalah peran gereja. Hemat penulis, gereja dan pendidikan memiliki keterkaitan erat, ada benang merah yang tidak dapat diputus. Sebab salah satu peran penting gereja adalah mendidik umatnya berdasarkan nilai-nilai kristiani. Pemerosotan karakter di tengah masyarakat dan bangsa Indonesia ini, mestilah membuat gereja turut prihatin dan berupaya menanggulanginya sebagai bagian dari panggilan kristiani di dalam Amanat Agung, yakni salah satunya adalah mengajar. Oleh karena itu, pendidikan karakter, di lingkungan gereja mesti peduli terhadap upaya menanggulangi berbagai perilaku tidak terpuji secara dini sebagai upaya menghasilkan pribadi-pribadi yang mewarisi karakter Kristus.

\footnotetext{
${ }^{7}$ Kalis Stevanus, "Tujuh Kebajikan Utama Untuk Membangun Karakter Kristiani Anak," BIA': Jurnal Teologi dan Pendidikan Kristen Kontekstual, Vol.1, No.1 (2018), 81.
} 


\section{METODE PENELITIAN}

Metode yang digunakan oleh penulis adalah metode penelitian kulitatif dengan sumber data berupa lingkungan alamiah. ${ }^{8}$ Sebagai sumber utama dalam kajian tulisan adalah Alkitab dan literatur. Penulis melakukan analisis data dengan memperbanyak informasi, mencari hubungan ke berbagai sumber, membandingkan, dan menemukan hasil atas dasar data sebenarnya. Dalam tulisan ini, penulis mengkaji peran gereja sebagai salah satu agen/pilar pendidikan dalam rangka upaya pencegahan dan penanggulangan kemerosotan moral yang terjadi di masyarakat. Proses analisis yang dilakukan oleh penulis adalah menggunakan berbagai sumber pustaka maupun elektronik yang terpercaya untuk mendukung analisis penulis.

\section{HASIL DAN PEMBAHASAN}

Sebelum menjelaskan strategi gereja dalam dalam pembentukan peserta didik yang unggul dan berkarakter berdasarkan perspektif kristiani, penulis terlebih dahulu menjelaskan hakikat dan tujuan pendidikan

${ }^{8}$ Sugiyono, Metode Penelitian Kuantitatif Kualitatif Dan R\&D (Bandung: Alfabeta, 2011),9.
Kristen, dan landasan Alkitab tentang pendidikan.

\section{Hakikat dan Tujuan Pendidikan Kristen}

Pengertian mengenai pendidikan dapat dilihat dari dua perspektif, yaitu pendidikan secara umum dan pengertian pendidikan Kristen. Secara umum istilah pendidikan berasal dari dua kata latin yaitu "educare" dan "educere". Kata pertama berarti, "merawat, memperlengkapi dengan gizi, agar sehat dan kuat. Yang kedua berarti, "membimbing keluar dari..." berdasarkan pengertian ini, maka secara umum pendidikan merupakan tindakan yang terencana, teratur, dan berkesinambungan untuk menaikkan kualitas dari manusia yang dididik. Dari tidak tahu menjadi tahu, dan kemudian mampu menerapkannya dalam kehidupan sehari-hari. Pendidikan berperan untuk menaikkan harkat dan martabat seseorang. Purwanto mendefinisikan pendidikan adalah segala usaha orang dewasa dalam pergaulannya dengan anak-anak untuk memimpin perkembangan jasmani dan

${ }^{9}$ Sidjabat, Strategi Pendidikan Kristen: Suatu Kajian Teologis-Filosofis. 44. 
rohani ke arah kedewasaan." 10 Pendidikan dipahami tidak hanya menyentuh wilayah intelektual saja melainkan juga memasuki ranah rohani, sehingga dengan pendidikan, kepribadian seseorang akan menjadi matang, dan siap untuk terjun ke masyarakat.

$$
\text { Bagaimana dengan pendidikan }
$$

Kristen? Di manakah perbedaan pendidikan Kristen dengan pendidikan non-Kristen? Apakah pendidikan Kristen memiliki filosofi (Worldview) khusus? Menurut penulis, pertanyaan-pertanyaan ini akan menolong para pelaku pendidikan baik pendidik maupun pemerhati pendidikan Kristen untuk memahami apa sebenarnya hakikat dan signifikansi Pendidikan Kristen.

Pendidikan Kristen seharusnya memiliki signifikansi yang menjadi pembeda dari pendidikan lainnya. Pembeda tersebut bukan di ranah kebijakan atau praktik pengelolaan pendidikannya, melainkan pada filosofinya (worldview) yang adalah motto penggeraknya. Stevanus dengan tegas menyatakan bahwa dasar utama dari pendidikan Kristen baik yang diselenggarakan secara informal di keluarga, non-formal di gereja maupun formal di sekolah adalah mendasarkan

${ }^{10}$ M. Ngalim Purwanto, Ilmu Pendidikan Teoritis Dan Praktis (Bandung: Remadja Karya, 1985), 11 . dirinya pada pribadi Yesus Kristus dan Alkitab sebagai standar kehidupan iman dan tingkah orang Kristen. ${ }^{11}$ Sebab itu, pendidikan Kristen yang mengabaikan Alkitab dan pribadi Yesus sebagai Tuhan dan Juruselamat, tidaklah dapat disebut suatu Pendidikan Kristen. Tanpa Yesus Kristus dan Alkitab, maka penyelenggaraan Pendidikan Kristen kehilangan hakikatnya.

Istilah Pendidikan Kristen, secara umum biasanya digunakan untuk pengajaran di sekolah-sekolah Kristen yang diselenggarakan di gereja maupun organisasi Kristen, yaitu yang menunjuk kepada pengajaran yang diberikan dalam suasana Kristen. ${ }^{12}$ Penjelasan istilah ini belum spesifik yang menunjukkan hakikat dari Pendidikan Kristen. Pendidikan Kristen tidak sekadar dijalankan dalam suasana Kristen, tapi merupakan suatu usaha mendidik manusia khususnya orang Kristen untuk berorientasi kepada kehidupan spiritualitas yang menghasilkan karakter Kristen. Suatu tindakan mendidik dengan menanamkan nilai-nilai kristiani sebagaimana diajarkan Alkitab.

Pazimino berpendapat bahwa Pendidikan Kristen merupakan usaha dan

${ }^{11}$ Kalis Stevanus, Menjadi Orangtua Bijak: Solusi Mendidik Dan Melindungi Anak Dari Pengaruh Pergaulan Buruk (Yogyakarta: Yayasan Pusataka Nusatama, 2016), 26.

${ }^{12}$ E.G. Homrighousen \& I.H. Enklaar, Pendidikan Agama Kristen (Jakarta: BPK Gunung Mulia, 2008), 19. 
sistimatis, ditopang oleh upaya rohani dan manusiawi untuk mentransmisikan pengetahuan, nilai-nilai, sikap-sikap keterampilan dan tingkah laku yang bersesuaian dengan iman Kristen, mengupayakan perubahan dan reformasi pribadi-pribadi, kelompok bahkan struktur oleh kuasa Roh Kudus, sehingga peserta didik sesuai dengan kehendak Allah, sebagaimana dinyatakan oleh Alkitab terutama di dalam Yesus Kristus. ${ }^{13}$ Lebih luas dan mendalam lagi, dikemukakan Gulo bahwa Pendidikan Kristen adalah suatu pendidikan yang bersumber pada Alkitab, yang juga berasaskan Pancasila, berwawasan nasional dan global serta menekankan pada terwujudnya tinggi iman, tinggi pengabdian, tinggi disiplin, dan tinggi ilmu/teknologi dari peserta didiknya sebagai pribadi yang utuh dan dinamis. $^{14}$

Tujuan pendidikan sangat penting sekali. Hamalik menyatakan bahwa tujuan pendidikan mengarahkan semua proses pendidikan. Berdasarkan tujuan pendidikan itu semua perencanaan pendidikan, perencanaan pengajaran,

${ }^{13}$ Sidjabat, Strategi Pendidikan Kristen: Suatu Kajian Teologis-Filosofis, 10.

${ }^{14}$ W. Gulo., "Penampakan Indentitas Dan Ciri Khas Dalam Penyelenggaraan Sekolah Kristen",Identitas Dan Ciri Khas Pendidikan Kristen Di Indonesia, Peny. Weinata Sairin (Jakarta: BPK Gunung Mulia, 2006), 85. kegiatan pendidikan dapat diarahkan kepada pembentukan manusia yang diharapkan masyarakat. Secara praktis proses pencapaian tujuan itu melalui suatu proses pengajaran yang direncanakan oleh sekolah. $^{15}$ Jadi pendidikan bukanlah sesuatu yang abstrak, melainkan tersistem dan terukur serta memiliki tujuan untuk memanusiakan manusia. Hal ini dapat dilihat dalam perspektif pendidikan secara umum. Dalam kekristenan sendiri, pendidikan Kristen memiliki tujuan lebih jauh dan bernilai kekal, yaitu menjadi serupa dengan Kristus. Verkuyl menyatakan bahwa pendidikan Kristen bertujuan agar peserta didik menjadi serupa dengan teladan Anak Allah (Roma 8:29; I Kor. 15:49; 2 Kor. 3:19). ${ }^{16}$

Pendapat yang sama mengenai tujuan dari Pendidikan Kristen diungkapkan oleh pakar Pendidikan Kristen yang cukup ternama, yakni Groome. Menurutnya, tujuan Pendidikan Kristen adalah untuk mendorong orang ke arah iman Kristen yang dewasa sebagai realitas yang hidup. Ditambahkan Groome, di dalam Pendidikan Kristen ada aspekaspek penting yang perlu dipahami, antara lain: 1) iman Kristen adalah pemberian

\footnotetext{
${ }^{15}$ Oemar Hamalik, Kurikulum Dan Pembelajaran (Jakarta: Bumi Askara, 2000.), 36.

${ }^{16} \mathrm{~J}$. Verkuyl, Aku Percaya (Jakarta: BPK Gunung Mulia, 1981), 177.
} 
Allah yang anugerah-Nya menyentuh batiniah seseorang dan membimbing ke arah hubungan hidup dengan Allah di dalam Yesus Kristus; 2) ada dimensi iman Kristen yang bersifat kognitif, yakni kegiatan percaya; 3) ada dimensi iman Kristen yang bersifat afektif, yakni kegiatan memercayakan; 4) ada dimensi iman Kristen yang berhubungan dengan tingkah laku, yakni kegiatan melakukan. ${ }^{17}$

Dari uraian di atas, dapat dikatakan bahwa Pendidikan Kristen memiliki tujuan melakukan kehendak Allah yakni mengubah pola pikir dan pola hidup seseorang. Pendidikan Kristen bukan sekedar memindahkan pengetahuan secara teoritis. Di dalamnya ada proses membentuk manusia yang bermutu secara Kristen. Dalam pendidikan Kristen, Alkitab menjadi landasan utama. Setiap mata pelajaran umum merupakan berada dalam wilayah hikmat umum, yang dikaruniakan Tuhan kepada semua manusia tanpa terkecuali. Namun Alkitab dilihat sebagai hikmat khusus atau penyataan khusus dari Allah untuk membawa seseorang mengenal Kristus dalam Roh dan Kebenaran. Pendidikan Kristen semestinya membawa transformasi intelektual dan spiritual. Inilah hakikat dan tujuan Pendidikan Kristen.

${ }^{17}$ Thomas Groome, Pendidikan Agama Kristen: Berbagi Cerita Dan Visi Kita (Jakarta: BPK Gunung Mulia, 2010), 107-111.

\section{Pendidikan dalam Perjanjian Lama}

Sebagaimana dikemukakan Wenas dan Darmawan, salah satu kitab di dalam Perjanjian Lama yang sering dijadikan dasar pendidikan anak di keluarga umat Israel adalah Kitab Ulangan pasal 6:4-9. Menurut Wenas dan Darmawan, di dalam ayat tersebut terdapat perintah ganda kepada bangsa Israel, yaitu (1) perintah untuk mengasihi Allah dengan segenap hati, jiwa, dan kekuatan (ay.5-6); (2) perintah kedua adalah untuk mengajarkan iman mereka dengan kepada anak-anak mereka ay.7-9. ${ }^{18}$ Dengan demikian, dapat dikatakan bahwa pendidikan anak merupakan perintah Tuhan bagi orangtua untuk mengajarkan kepada anak mereka secara intensif dalam setiap kesempatan seperti di rumah, perjalanan, berbaring, bangun, dan sebagaianya sebagai momen mengajar anak.

Menurut Sanjaya pendidikan dalam konteks Israel dapat berdimensi ganda; pendidikan tidak hanya menyangkut dimensi etis, tetapi juga dimensi historis. Sejak usia dini, orang Israel sudah diajarkan tentang karya penyelamatan Allah dalam sejarah nenek moyang mereka

\footnotetext{
${ }^{18}$ Maria Lidya Wenas dan I Putu Ayub Darmawan, "Signifikansi Pendidikan Anak dalam Perspektif Alkitab," Evangelikal: Jurnal Teologi Injili dan Pembinaan Warga Jemaat Vol.1, Nomor 2 (2017): 122.
} 
(dimensi historis) sekaligus diajak untuk belajar hidup dan berkelakuan pantas (dimensi etis) sebagai konsekuensi logis dari pengalaman akan Allah yang menyelamatkan itu. Dengan kata lain, konteks penceritaan kembali kisah-kisah penting dalam sejarah Israel tidak sekadar untuk konsumsi kognitif (pengetahuan) belaka, tetapi berusaha membawa anakanak untuk masuk ke dalam pengalaman nenek moyang mereka melalui peran orang tua. ${ }^{19}$ Dengan demikian pendidikan dalam konteks Israel ialah memberikan pengenalan akan Allah dalam kehidupan sejarah bangsanya, dan mengingat akan jasa-jasa Allah kepada nenek moyang mereka. Dan pendidikan ini diajarkan dimulai oleh orangtua, karena orangtua dianggap sebagai wakil Tuhan (Ulangan 6:4-9). Terkait dengan pendidikan dalam konteks Israel kuno, Nili Shupak berpendapat bahwa tidak ada bukti aktual tentang keberadaan institusi sekolah pada era Bait Allah pertama seperti halnya yang ditemukan di Mesir dan Mesopotamia. ${ }^{20}$ Hal serupa dipertegas oleh Crenshaw, demikian: "Banyak orang bertanya, 'Apa

${ }^{19} \mathrm{~V}$. Indra Sanjaya, "Pendidikan Iman: Belajar Dari Tradisi Kuno," Wacana Biblika Vol.9, No.1 (2009): 9.

${ }^{20}$ Nili Shupak, "Learning Methods In Ancient Israel,' Vetus Testamentum Vol.53, no. No.3 (2003): 416.

https://doi.org/10.1163/156853303768266 380. yang dapat kita ketahui tentang pendidikan Israel kuno?' Jawabannya: tidak banyak."21 Suatu pernyataan yang sama juga dikemukakan oleh Davies dalam tulisannya berjudul "Were There Schools in Ancient Israel?". Davies menemukan bahwa banyak ahli yang cenderung skeptis terkait isu keberadaan sekolah pada zaman Israel kuno. ${ }^{22}$ Dukungan pendapat ini juga muncul dari Rollston yang melakukan penyelidikan terhadap sejumlah literatur yang mengadakan penelitian tentang keberadaan sekolah di Israel kuno. Dalam penelusurannya, disebut bahwa para ahli tidak memiliki atau menemukan bukti yang meyakinkan tentang keberadaan sekolah di Israel kuno: "Golka menulis bahwa tidak ada referensi untuk kata "sekolah" dalam Alkitab Ibrani. Weeks menyatakan bahwa tidak cukup bukti dan alasan untuk menduga bahwa sekolah tersebut benar-benar ada. Sementara Jamieson-Drake berteori bahwa "sekolah

\footnotetext{
${ }^{21}$ Barry W. Holtz, "Bible: Teaching the Bible in Our Times,' ," in In International Handbook of Jewish Education, ed. and Alex Pomson ed. Helena Miller, Lisa D. Grant (Berlin: Springer Science \& Business Media, 2011), 373.

${ }^{22}$ G. I. Davies, "Were There Schools in Ancient Israel," in In Wisdom in Ancient Israel, ed. ed. John Day and and H. G. M. Williamson Robert P. Gordon (Cambridge: Cambridge University Press, 1995), 199.
} 
pasti berlokasi di Yerusalem, jika sekolah tersebut memang ada." 23

Hal ini memperlihatkan bahwa para ahli dominan berpendapat bahwa tidak ada sekolah formal pada zaman Israel kuno. Namun Seto Marsunu tampaknya kurang sependapat dengan mengatakan bahwa pendidikan Israel kuno memang lebih banyak bercorak informal, namun bukan berarti pendidikan formal tidak dikenal di Israel kuno. Warisan iman berupa tulisan dan sekarang diterima sebagai Kitab Suci menjadi bukti tentang adanya sekolah di Israel kuno. ${ }^{24}$ Crenshaw yang menyebut bahwa kendati Perjanjian Lama tidak memperlihatkan institusi sekolah sebagai tempat pendidikan formal anak Yahudi, akan tetapi informasi tentang hal itu dapat ditemukan dalam kitab deuterokanonika yaitu Bin Sirakh. ${ }^{25}$ Bahkan, menurut ahli lain, Aberbach, cikal bakalnya dapat ditelusuri mulai dari era Ezra. Pada era Ezra terdapat sekolah informal yang diperuntukkan untuk melatih para imam dan sofrim (ahli kitab) dimana mereka belajar membaca Taurat secara institusional (sekitar abad ke-5 SM). Para

\footnotetext{
${ }^{23}$ Christopher A. Rollston, Writing and Literacy in the World of Ancient Israel: Epigraphic Evidence from the Iron Age, (Atlanta: Society of Biblical Literature, 2010), 91.

${ }^{24}$ Y.M. Seto Marsunu, "Pendidikan Iman Anak Dalam Perjanjian Lama Dan Tradisi Yahudi," Wacana Biblika Vol.13, no. No.4 (2013): 147.

${ }^{25}$ James L. Crenshaw, "“Education in Ancient Israel,"' Journal of Biblical Literature Vol.104, no. No.4 (1985): 601.
}

Sofrim inilah yang kemudian mendirikan institusi pendidikan Yahudi dan pada era Bin Sirakh (sekitar 200 SM), membangun sidikitnya satu sekolah hikmat (Wisdom School) di Israel. Hanya saja sekolah yang didirikan ini adalah untuk orang dewasa, bukan untuk anak-anak. ${ }^{26}$

Terlepas dari perdebatan adanya sekolah formal pada zaman Israel kuno, mandat implisit pendidikan iman anak tampaknya dapat ditemukan dalam paragraf pertama dari Shema Yisrael (Ul. 6: 6-9): “Apa yang kuperintahkan kepadamu pada hari ini haruslah engkau perhatikan, haruslah engkau mengajarkannya berulang-ulang kepada anak-anakmu dan membicarakannya apabila engkau duduk di rumahmu, apabila engkau sedang dalam perjalanan, apabila engkau berbaring dan apabila engkau bangun. Haruslah juga engkau mengikatkannya sebagai tanda pada tanganmu dan haruslah itu menjadi lambang di dahimu, dan haruslah engkau menuliskannya pada tiang pintu rumahmu dan pada pintu gerbangmu."27 Bahkan menurut Roland de Vaux, ayat tersebut telah menjadi salah satu bukti bahwa budaya menulis sudah dikenal dan dimiliki

\footnotetext{
26 Aberbach, Jewish Education and History: Continuity, Crisis and Change. 2

${ }^{27}$ I Putu Ayub Darmawan, "“Pembelajaran Memorisasi Dalam Ulangan 6:6-9,", EPIGRAPHE: Jurnal Teologi dan Pelayanan Kristiani Vol.3, no. No.1 (2019): 21.
} 
oleh para kepala keluarga pada zaman Israel kuno. Untuk memperkuat pandangannya, De Vaux juga mengutip kitab Hakim-hakim 8: 13-14 tentang pemuda dari Sukot yang ditangkap dan diinterogasi oleh Gideon, yang kemudian menuliskan nama-nama para pemuka dan para tua-tua di Sukot. ${ }^{28}$

Di dalam menempuh pendidikan formal institusi, anak-anak Yahudi melalui 2 tahapan pendidikan sebagaimana yang dituliskan oleh Abineno bahwa anak-anak kecil (dari enam atau tujuh tahun) mendapat pengajaran dari guruguru Torah. Maksud pengajaran ini ialah seperti yang kita katakan di situ-bukan untuk memberikan pengetahuan umum kepada anak-anak, tetapi pengetahuan tentang Torah. Pengetahuan ini terdiri dari pembacaan dan penghafalan nas Torah secara harfiah. Sesuai dengan itu "sekolah dasar" ini disebut "beth ha sefer" (rumah buku). anak-anak Yahudi melalui 2 tahapan pendidikan sebagaimana disebut oleh Abineno bahwa anak-anak kecil (dari enam atau tujuh tahun) mendapat pengajaran dari guru-guru Torah. Maksud pengajaran ini ialah bukan untuk memberikan pengetahuan umum kepada anak-anak, tetapi pengetahuan tentang

\footnotetext{
${ }^{28}$ Roland De Vaux, Ancient Israel: Its Life and Instructions (Grand Rapids: eerdmans Publishing, 1997), 49.
}

Torah. Pengetahuan ini terdiri dari pembacaan dan penghafalan teks-teks Torah secara harafiah. Sesuai dengan itu "sekolah dasar" ini disebut "beth ha sefer" (rumah buku). ${ }^{29}$ Torah harus dipelajari secara harfiah. Pengajaran yang lebih tinggi diberikan dalam "beth ha midrasy" (rumah pengajaran). Maksud pengajaran di sini ialah bukan saja untuk membaca dan menghafalkan Torah, melainkan juga untuk mengetahui arti dan maknanya. Untuk mengetahui arti dan makna Torah bukanlah suatu kegiatan yang berdiri sendiri. Ia mempunyai hubungan dengan kebiasaan-kebiasaan hidup Yahudi, yang merupakan latar belakangnya. Sejak kecil anak-anak telah dibiasakan untuk mentaati peraturan-peraturan agama. ${ }^{30}$ Berdasarkan hal ini dapat dilihat bahwa pendidikan secara kompreherensif mendapat bagian yang sangat penting dalam kehidupan bangsa Israel.

\section{Pendidikan dalam Perjanjian Baru}

Dalam Kitab Perjanjian Baru, pendidikan juga mendapat tempat yang penting. Humes menulis, "Namun jelaslah bahwa pendidikan sungguh dipentingkan

${ }^{29} \mathrm{Jl}$. Ch. Abineno, Sekitar Katekese Gerejawi Pedoman Guru (Jakarta: BPK Gunung Mulia, 2012), 62.

${ }^{30}$ Ibid. 63. 
dalam Perjanjian Baru. Mengenai mengajar disebut lebih dari tiga ratus kali dan guru disebut lebih dari empat puluh kali."31 Oleh Homrighausen dan Enklaar sistem pendidikan dalam Perjanjian Baru dibagi ke dalam 3 masa: masa Tuhan Yesus, masa Paulus, dan masa gereja mula-mula. ${ }^{32}$ Dengan demikian pendidikan Kristen di masa Perjanjian Baru tida terpisahkan dari Pribadi Yesus Kristus sebagai Guru Agung (Yohanes 3:2). Tuhan Yesus adalah pusat atau atau inti berita, jiwa, model dari pendidikan Kristen. Injil Matius mencatat bahwa sebagai Guru Agung Yesus mengajar dengan penuh kuasa, kontras dengan para ahli Taurat (Matius 7:29). Tuhan Yesus mengajar dengan sangat kreatif. Metode yang Ia gunakan dangan relevan untuk digunakan oleh pengajar Kristen hari ini. Ada kalanya Tuhan Yesus mengajar dengan bercerita, Ia memakai perumpamaan-perumpamaan yang diambil dari kehidupan keseharian orang-orang pada masa itu, kemudian Ia mengajukan pertanyaan-pertanyaan untuk memancing daya nalar yang mendengarkan-Nya. Dalam kesempatan lain juga Tuhan Yesus menggunakan anak kecil sebagai alat peraga untuk menegur para murid-Nya. Tuhan Yesus membasuh kaki murid-murid-Nya untuk menjelaskan

\footnotetext{
${ }^{31}$ L. Humes, Arah Pendidikan Kristen Falsafah Pendidikan Kristen Dan Dasar Alkitabiahnya (Batu Malang: YPPII,1992), 42. ${ }^{32} \mathrm{Ibid}, 16$.
}

kedalaman dari sebuah kerendahan hati dan pelayanan.

Pengajaran Tuhan Yesus sangat efektif dan akhirnya banyak diminati, terlihat dari banyaknya orang yang mengikuti Dia. Hal tersebut salah satunya terlihat dalam peristiwa Ia memberi makan 5000 orang dengan 5 roti dan 2 ikan. Bukan saja karena penuh kuasa, melainkan juga terlihat bahwa metode yang digunakan Tuhan Yesus sangat menarik dan mendorong para pendengarnya untuk berpikir dan mempertimbangkan apa yang Ia ajarkan.

Dalam masa Rasul Paulus, pendidikan Kristiani juga tersirat sebagai sesuatu yang penting. Paulus sendiri adalah seorang yang terdidik oleh Gamaliel. Paulus dalam banyak kesempatan berkhotbah kepada orang Yahudi juga kepada orang Yunani, dan Paulus dapat menjelaskan iman Kristen kepada orang-orang Yunani yang berwawasan filsafat sehingga dapat menerima Yesus Kristus sebagai Tuhan dan Juruselamat. ${ }^{33}$ Penekanan dalam kehidupan jemaat Perjanjian Baru adalah bagaimana iman Kristen secara dialektika memengaruhi dan dipengaruhi dengan konteks yang selalu berubah serta bagaimana kesinambungan/kontinuitas iman Kristen dalam menghadapi

${ }^{33}$ E.G. Homrighousen \& I.H. Enklaar, Pendidikan Agama Kristen, 72. 
perubahan dan tantangan pada masa-masa tertentu. $^{34}$

\section{Peran Gereja dalam Pendidikan}

Gereja harus berperan banyak untuk membekali para guru agar sehat secara rohani. Dalam UU No. 20 Tahun 2003 seorang guru/pendidik dituntut harus sehat secara jasmani dan rohani. ${ }^{35}$ Contoh kegiatan pembinaan guru agama Kristen dilakukan oleh Stephen Tong Evangelistic Ministries International (STEMI) pada 11 - 16 November 2014. Dalam kegiatan tersebut para pembicara memberikan penyegaran rohani, semangat dan kesadaran akan panggilannya sebagai guru. $^{36}$ Guru yang sehat rohani akan menjadikan pekerjaannya sebagai wujud kasih. Guru akan mengasihi murid-murid yang diajarnya. Dengan kasih guru mengajar murinya dengan totalitas hidupnya. Teladan ini ditunjukkan oleh Yesus Sang Guru Agung. Yesus mengajar murid-muridnya dengan penuh kasih. ${ }^{37}$

\footnotetext{
${ }^{34}$ Robert W. Pazmino, FONDASI PENDIDIKAN KRISTEN; SUATU PENGANTAR DALAM PERSPEKTIF INJILI (Jakarta: (Sekolah Tinggi Teologi Bandung dan PT BPK Gunung Mulia, 2012), 78.

${ }^{35}$ Undang-Undang No. 20 Tahun 2003 Tentang Sistem Pendidikan Nasional..

${ }^{36}$ I Putu Ayub Darmawan, "'Pembelajaran Memorisasi Dalam Ulangan 6:6-9,210.

${ }^{37}$ Ibid.
}

Gereja harus memiliki rasa tanggungjawab terhadap anak-anak putus sekolah yang jumlahnya tidak sedikit. Faktor kemiskinan menjadi salah satu penyebab. Tanggung jawab sekolah Kristen dalam melengkapi anak didiknya diungkapkan oleh Holmes adalah:

1. Kemampuan untuk mengembangkan potensi yang ada pada dirinya dalam bentuk talenta, karunia dan profesi.

2. Wawasan baru bagi peserta didik, berkaitan dengan kemampuannya untuk secara efektif memanfaatkan waktu senggangnya demi kemuliaan Kristus.

3. Pemahaman akan panggilan hidup sebagai warga negara yang bertanggungjawab.

4. Dorongan-dorongan guna memungkinkan anak didik menjadi warga negara yang tangguh, serta memiliki pengetahuan tentang identitas dan peranan gereja dalam dunia ini.

5. Wawasan-wawasan baru yang akan membantu anak didik dalam menghadapi dinamika perubahan dan tantangan zaman, serta bersikap kritis terhadap tren yang berkembang di tengah-tengah masyarakat. 
6. Membimbing anak didik agar dapat memiliki pandangan hidup yang menyeluruh, menyatu, dan yang dapat diandalkan dalam memainkan peranannya bagi pembangunan dan pembaharuan (transformasi) masyarakat. ${ }^{38}$

Gereja dalam perannya dalam pendidikan nasional, peran aktif sebagai tanggung jawab moral adalah dengan terlibat dalam peningkatan mutu guru menjadi guru yang kompeten, guru yang sehat rohaninya. Untuk meningkatkan kompetensi tersebut, gereja dapat melakukan training guru, pembinaan guru agama Kristen secara berkelanjutan. Gereja hadir bagi guru untuk menolong dan memimpin guru dalam pertumbuhan rohani sehingga guru yang sehat rohani dapat menjadi mitra gereja dalam mendidik warga gereja (murid-murid Kristen) yang belajar di sekolah. Peran gereja berikutnya dalam pendidikan nasional adalah penyelenggaraan sekolah yang bermutu dan penyelenggaraan sekolah sebagai pelayanan gerejawi. Melalui penyelenggaraan sekolah sebagai pelayanan gerejawi, gereja dapat menjawab kebutuhan masyarakat dalam

${ }^{38}$ Alfius Areng Mutak, “Gereja Dan Pendidikan Kristen'," Jurnal Theologia Aletheia, Vol.7, no. No.12 (2005): 22. bidang pendidikan khususnya penanganan anak putus sekolah. ${ }^{39}$

\section{Pendidikan Karakter Kristaini}

Dalam konteks Kristen sebagaimana penulis telah jelaskan sebelumnya bahwa spirit pendidikan Kristen berpusat kepada Kristus.

Pendidikan Kristen memegang peranan yang sangat penting. Setelah menerima Kristus sebagai Tuhan dan Juruselamat pribadinya, remaja perlu terus dibimbing agar pemulihan gambar dan rupa Allah dalam diri mereka (restoration) dan pemulihan relasi mereka dengan Tuhan, sesama, dan diri mereka sendiri (reconciliation) dapat terjadi. ${ }^{40}$ Dalam pendidikan Kristen, proses restorasi dan rekonsiliasi ini dilakukan melalui pemberitaan Injil kepada remaja agar mereka memahami dan menerima dengan iman bahwa Kristus mengasihi mereka. Namun hal ini tidak bisa hanya dilakukan melalui penjelasan konsep-konsep teologis semata melainkan hati mereka juga butuh untuk disentuh agar bisa merasakan dan mengalami sendiri akan kasih Allah dalam

\footnotetext{
${ }^{39}$ I Putu Ayub Darmawan, "“Pembelajaran Memorisasi Dalam Ulangan 6:6-9,.214.

${ }^{40}$ Novel Priyatna, "Peran Guru Kristen Sebagai Agen Restorasi Dan Rekonsiliasi Dalam Mengembangkan Karakter Kristus Pada Diri Remaja Sebagai Bagian Dari Proses Pengudusan," A Journal of Language, Literature, Culture, and Education POLYGLOT Vol.13, no. No.1 (2017), 4.
} 
diri mereka. Oleh karena itu mereka sangat membutuhkan role models yang dapat mereka lihat dan teladani dalam mengaplikasikan prinsip-prinsip kebenaran firman Tuhan melalui interaksi seharihari. ${ }^{41}$ Dalam konteks sekolah, maka guru menjadi role models yang sangat efektif, karena para siswa memiliki waktu yang cukup banyak untuk berinteraksi dengan gurunya. Setiap hari guru dan siswa berinteraksi secara langsung, dan perlahan siswa akan terpengaruh dengan karakter gurunya. Begitu pula sebaliknya, ketika guru berkarakter buruk, siswa akan cenderung meniru hal tersebut. Karakter seorang guru berkaitan erat dengan peran guru dalam membentuk karakter siswa. ${ }^{42}$

Karakter Kristen yang sejati hanya akan dapat berkembang melalui orangorang yang sudah lahir baru. ${ }^{43}$ Selain itu guru merupakan contoh teladan di sekolah maupun di lingkungan masyarakat. Masyarakat akan menilai setiap perilaku guru karena masyarakat berpikir bahwa seorang guru seharusnya mengajar hal yang benar sehingga kehidupannya juga

${ }^{41}$ Ibid.

42"Kiki Debora Dan Chandra Han, Pentingnya Peranan Guru Kristen Dalam Membentuk Karakter Siswa Dalam Pendidikan Kristen: Sebuah Kajian Etika Kristen," Diligentia: Journal of Theology and Christian Education, (2020)..

${ }^{43}$ Kalis Stevanus, "Samuel Soukotta Sosok Pendidik Karakter Kristen." harus benar. $^{44}$ Guru mutlak menjadi teladan bagi para siswanya, "keteladanan pendidik adalah kompas yang menuntun para peserta didik dalam menjalani personal dan sosialnya di kemudian hari sebagai insan yang beriman, berintegritas, dan bermoral. ${ }^{45}$

\section{KESIMPULAN}

Berdasakarkan kajian dalam tulisan ini, penulis melihat bahwa pendidikan karakter penting dan mendesak bagi masyarakat Indonesia, termasuk gereja sebagai komunitas iman Kristen. Karakter penting untuk dimiliki oleh warga gereja sebagai bentuk kesaksian dan juga sebagai bentuk proteksi bagi generasi penerus gereja di masa depan sehingga tidak terjerumus pada tindakan-tindakan negatif. Khususnya generasi muda merupakan kelompok yang rentan terhadap dampak perkembangan sosial dengan segala pengaruh negatifnya. Dengan memiliki karakter kristiani, maka perkembangan zaman seperti media sosial bukan lagi ancaman tetapi menjadi kesempatan yang

\footnotetext{
44،Kiki Debora Dan Chandra Han, Pentingnya Peranan Guru Kristen Dalam Membentuk Karakter Siswa Dalam Pendidikan Kristen: Sebuah Kajian Etika Kristen."

${ }^{45}$ B Samho, "Pendidikan Karakter Dan Kultur Globalisasi: Inspirasi Dari Ki Hadjar Dewantara,", Melintas, (2014): 6.
} 
baik untuk mengembangkan media sosial sebagai sarana dalam belajar menanamkan karakter baik seperti penguasaan diri, toleransi, empati, suka menolong, terbuka, dan sebagainya. Setelah penulis melakukan kajian ini, penulis menemukan bahwa pokok persoalan sebenarnya bukan pada perkembangan media sosial tetapi pokok persoalannya adalah terletak kepada problem karakter yang harus ditanggulangi sejak dini. Dan gereja, sebagai lembaga pendidikan non-formal memiliki peran strategis dalam tugasnya (mengajar) untuk membangun karakter kristiani bagi warganya, yakni menghasilkan insan-insan yang berkarakter unggul sesuai nilai-nilai kristiani.

Tulisan ini bisa menjadi sebagai kontribusi kepada agen pendidikan, juga para pelaku pendidikan dalam meningkatkan kualitas pengajarannya berbasis pada nilai-nilai kristiani demi memajukan pendidikan di era post modern ini sehingga studi analisis tentang signifikansi peran gereja dalam pendidikan karakter ini dapat bermanfaat dan menjadi referensi kepada para peneliti berikutnya.

\section{DAFTAR PUSTAKA}

Alfius Areng Mutak. "“Gereja Dan Pendidikan Kristen',.” Jurnal Theologia Aletheia, Vol.7, no. No.12 (2005)

B Samho. “"Pendidikan Karakter Dan
Kultur Globalisasi: Inspirasi Dari Ki Hadjar Dewantara,." Melintas, (2014)

Barry W. Holtz. "'Bible: Teaching the Bible in Our Times,' ,." In In International Handbook of Jewish Education, edited by and Alex Pomson ed. Helena Miller, Lisa D. Grant, 373. Berlin: Springer Science \& Business Media, 2011.

Christopher A. Rollston. Writing and Literacy in the World of Ancient Israel: Epigraphic Evidence from the Iron Age,. Atlanta: Society of Biblical Literature, 2010.

Daniel Nuhama. "Pengutamaan Dimensi Karakter Dalam Pendidikan Agama Kristen.” Jurnal Jaffray Vol.16, no. No.1 (n.d.)

E.G. Homrighousen \& I.H. Enklaar. Pendidikan Agama Kristen. Jakarta: BPK Gunung Mulia, 2008.

G. I. Davies. "Were There Schools in Ancient Israel,." In In Wisdom in Ancient Israel, edited by ed. John Day and and H. G. M. Williamson Robert P. Gordon, 199. Cambridge: Cambridge University Press, 1995.

Groome, Thomas. Pendidikan Agama Kristen: Berbagi Cerita Dan Visi Kita. Jakarta: BPK Gunung Mulia, 2010.

Gulo., W. "Penampakan Indentitas Dan Ciri Khas Dalam Penyelenggaraan Sekolah Kristen",Identitas Dan Ciri Khas Pendidikan Kristen Di Indonesia, Peny. Weinata Sairin. Jakarta: BPK Gunung Mulia, 2006.

Hamalik, Oemar. Kurikulum Dan Pembelajaran. Jakarta: Bumi Askara, n.d.

I Putu Ayub Darmawan. " Pembelajaran Memorisasi Dalam Ulangan 6:6-9,.", EPIGRAPHE: Jurnal Teologi dan Pelayanan Kristiani Vol.3, no. No.1 
Strategi Pendidikan Kristen dalam Pembentukan Warga Gereja yang Unggul dan Berkarakter Berdasarkan Perspektif Kristiani| 65

(2019)

V. Indra Sanjaya. “"'Pendidikan Iman:

Belajar Dari Tradisi Kuno,." Wacana

Biblika Vol.9, no. No.1 (2009): 9.

J. Verkuyl. Aku Percaya. Jakarta: BPK Gunung Mulia, 1981.

James L. Crenshaw. "“Education in Ancient Israel,."' Journal of Biblical Literature Vol.104, no. No.4 (1985)

Jl. Ch. Abineno. Sekitar Katekese Gerejawi Pedoman Guru. Jakarta: BPK Gunung Mulia, 2012.

kalis Stevanus. Menjadi Orangtua Bijak: Solusi Mendidik Dan Melindungi Anak Dari Pengaruh Pergaulan Buruk. Yogyakarta: Yayasan Pusataka Nusatama, 2016.

Kalis Stevanus. "Pemimpin Kristen Di Era Globalisasi." Jurnal : The Message Vo.2, no. No.1 (2014)

"Samuel Soukotta Sosok Pendidik Karakter Kristen." In Festschrift: Sam Soukotta Sang Pemimpin Karakter Kristen, edited by Hendro H. Siburian dan Firman Panjaitan, 21. 1st ed. Surakarta: Sekolah Tinggi Teologi Tawangmangu, 2020.

L. Humes. Arah Pendidikan Kristen Falsafah Pendidikan Kristen Dan Dasar Alkitabiahnya. Batu Malang: YPPII,1992, 1992.

M. Ngalim Purwanto. Ilmu Pendidikan Teoritis Dan Praktis. Bandung: Remadja Karya, 1985.

Maria Lidya Wenas dan I Putu Ayub Darmawan. "SIGNIFIKANSI PENDIDIKAN ANAK DALAM PERSPEKTIF ALKITAB."

Evangelikal: Jurnal Teologi Injili dan Pembinaan Warga Jemaat Vol.1, no. Nomor 2 (2017)
Nili Shupak. "“Learning Methods In Ancient Israel,." Vetus Testamentum Vol.53, no. No.3 (2003)

Novel Priyatna. "Peran Guru Kristen Sebagai Agen Restorasi Dan Rekonsiliasi Dalam Mengembangkan Karakter Kristus Pada Diri Remaja Sebagai Bagian Dari Proses Pengudusan." A Journal of Language, Literature, Culture, and Education POLYGLOT Vol.13, no. No.1 (2017).

Robert W. Pazmino. FONDASI PENDIDIKAN KRISTEN; SUATU PENGANTAR DALAM PERSPEKTIF INJILI. Jakarta: (Sekolah Tinggi Teologi Bandung dan PT BPK Gunung Mulia, 2012.

Roland De Vaux. Ancient Israel: Its Life and Instructions. Grand Rapids: eerdmans Publishing, 1997.

Sidjabat, B.S. Strategi Pendidikan Kristen: Suatu Kajian Teologis-Filosofis. Yogyakarta: Andi Offset, 1996.

Stevanus, Kalis. "Tujuh Kebajikan Utama Untuk Membangun Karakter Kristiani Anak." BIA': Jurnal Teologi dan Pendidikan Kristen Kontekstual (2018).

Sugiyono. Metode Penelitian Kuantitatif Kualitatif Dan R\&D. Bandung: Alfabeta, 2011.

Y.M. Seto Marsunu. “"Pendidikan Iman Anak Dalam Perjanjian Lama Dan Tradisi Yahudi." Wacana Biblika Vol.13, no. No.4 (2013)

"Kiki Debora Dan Chandra Han, Pentingnya Peranan Guru Kristen Dalam Membentuk Karakter Siswa Dalam Pendidikan Kristen: Sebuah Kajian Etika Kristen.” Diligentia: Journal of Theology and Christian Education (2020). 
66 | SANCTUM DOMINE: Jurnal Teologi, vol. 10, no. 1 (2020)

Undang-Undang No. 20 Tahun 2003

Tentang Sistem Pendidikan Nasional., n.d.

Undang-Undang Sisdiknas (Sistem Pendidikan Nasional). Sinar Grafika, 2007. 